\title{
Thermal performance optimization of hollow clay bricks made up of paper waste
}

\author{
Mucahit Sutcu $^{\mathrm{a}, *}$, Juan José del Coz Díaz ${ }^{\mathrm{b}}$, Felipe Pedro Álvarez Rabanal ${ }^{\mathrm{b}}$, \\ Osman Gencel ${ }^{\mathrm{c}}$, Sedat Akkurt ${ }^{\mathrm{d}}$ \\ a Department of Materials Science and Engineering, Izmir Kâtip Çelebi University, 35620 Izmir, Turkey \\ ${ }^{\mathrm{b}}$ Department of Construction, University of Oviedo, 33204 Gijón, Spain \\ ${ }^{c}$ Department of Civil Engineering, Bartin University, 74100 Bartin, Turkey \\ d Department of Mechanical Engineering, Izmir Institute of Technology, 35430 Izmir, Turkey
}

\section{A R T I C L E I N F O}

\section{Article history:}

Received 19 July 2013

Received in revised form 26 January 2014

Accepted 6 February 2014

\section{Keywords:}

Lightweight hollow clay brick

Paper waste

Thermal conductivity

Thermal transmittance

Optimization

\begin{abstract}
A B S T R A C T
In this paper, the thermal behavior of hollow clay bricks made up of paper waste has been studied and their thermal performance has been optimized. On the one hand, both strength and thermal properties of different paper waste concentrations have been obtained by means of laboratory tests. Thermal conductivity of the microporous brick materials with additives produced in this study reduced from $0.68 \mathrm{~W} / \mathrm{m} \mathrm{K}$ to $0.39 \mathrm{~W} / \mathrm{m} \mathrm{K}$ compared with that of the sample without additives. On the other hand, the finite element method (FEM) has been applied to the nonlinear numerical thermal analysis of three different hollow bricks, including radiation and convection phenomena inside holes. Next, using the design of experiments (DOE) over the FEM models, several parameters such as the material conductivity, the convection and radiation properties and the mean brick temperature have been studied. In general, the thermal resistance is a nonlinear function that depends on the geometry of the recesses, the material properties and the temperature distribution. In all analyzed cases, minimizing the material thermal conductivity of bricks and decreasing the recesses surface radiation emissivity caused a lower thermal transmittance in the brick. Finally, the most important conclusions and the main findings of this research are exposed.
\end{abstract}

(c) 2014 Elsevier B.V. All rights reserved.

\section{Introduction}

Energy saving and energy efficiency of buildings are recently two of the most important issues in the world because of both economic and environmental concerns. One of the major sectors that consume a significant amount of total energy in the world is the building sector due to the largest end user of energy, key driving economic sector and improving quality of life. For instance, this sector represents almost one third of the total energy consumed in Turkey and EU countries, and this energy is eventually used for heating and cooling of buildings [1-4]. Consumption of energy from buildings constitutes about 33\% of total consumption with about half of this lost through the walls [5]. Building insulating materials such as concrete insulating blocks, pumice, polymeric foam boards and lightweight clay bricks that manufactured in various combinations are used to reduce heat transfer [6]. In consequence, for

\footnotetext{
* Corresponding author. Tel.: +90 232 3293535x3732; fax: +90 2323293999.

E-mail addresses: mucahitsutcu@gmail.com, mucahit.sutcu@ikc.edu.tr (M. Sutcu).
}

housing, residential and public structures there are a great interest in lightweight building materials with good thermal properties, which fulfills all strength and serviceability requirements [7].

Construction industry generally uses large amounts of clay brick in most of buildings [8]. If these bricks are improved by proper processing, they can have significantly lower thermal conductivity and transmittance properties which mean a lower heat loss through the walls of houses [9]. When pores are introduced into bricks their thermal conductivities are reduced. This can be done by either microporosities, like the closed pores created by pore-making additives before bricks were fired, or by introducing perforations extending through the brick like in the case of vertically perforated brick $[8,10]$. In the former, when pore-making additives are used in clay brick, organic parts burn and leave micrometer scale pores behind which help reduce thermal conductivity of the brick [11-13]. The latter is used extensively by the brick industry to save clay material, to decrease density of the product or to reduce thermal conductivity of the brick. Vertically perforated bricks are manufactured extensively in both Turkey and the EU $[2,8]$. These are excellent low-cost, environment friendly and energy saving construction materials. These properties are derived from their 


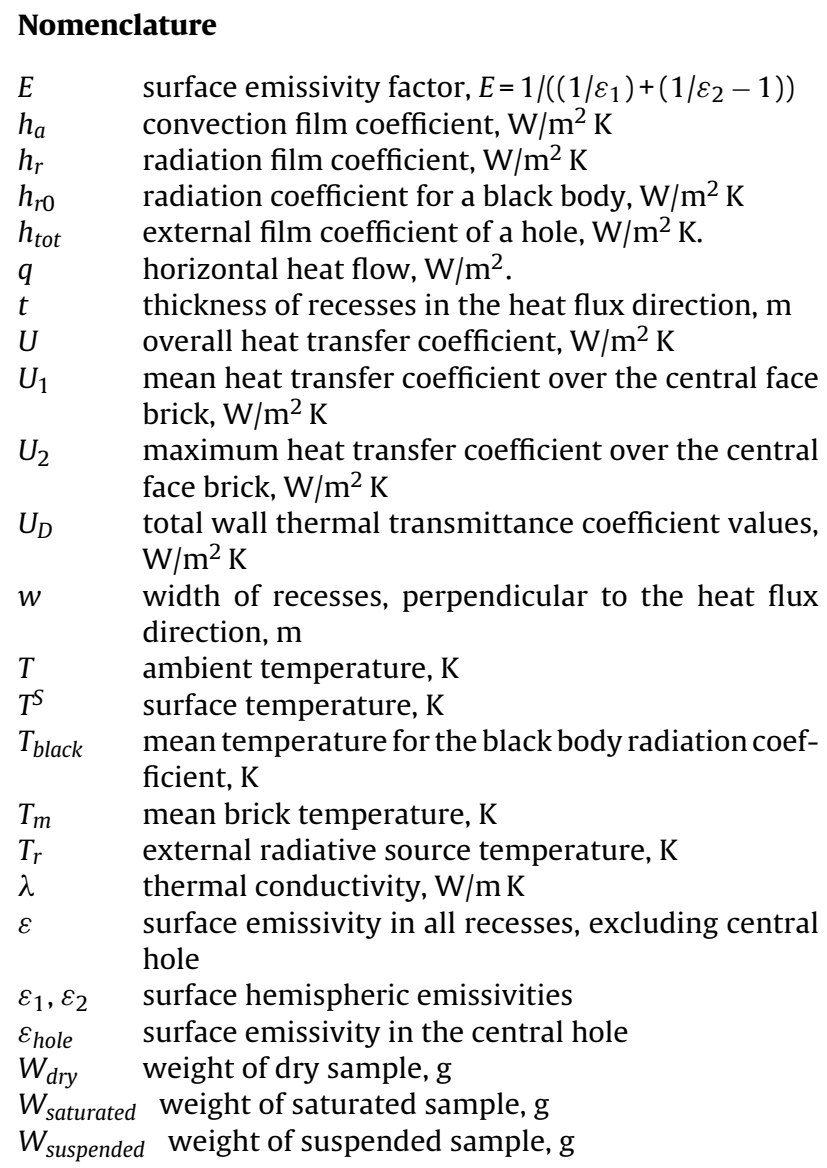

lightweight of $500-1000 \mathrm{~kg} / \mathrm{m}^{3}$ obtained by having different types of continuous vertical perforations. Different vertical perforation designs in brick lead to different thermal conductivities. These perforations act as barriers to heat flow by conduction through the walls of the brick. For the vertically perforated insulating clay brick, total wall thermal transmittance coefficient values $\left(U_{D}\right)$ are between 0.4 and $0.7 \mathrm{~W} / \mathrm{m}^{2} \mathrm{~K}$ according to regional climate differences preferred for Turkey [14,15]. The thermal conductivities of the bricks show the difference as depending on their unit weights or densities. According to the TS 825 standard, for instance, the equivalent thermal conductivity values of the bricks with densities of $2400 \mathrm{~kg} / \mathrm{m}^{3}$ (solid brick) and $700 \mathrm{~kg} / \mathrm{m}^{3}$ (insulating brick) are about $1.40 \mathrm{~W} / \mathrm{m} \mathrm{K}$ and $0.24 \mathrm{~W} / \mathrm{m} \mathrm{K}$, respectively [15].

This study is focused on investigating the thermal performance of vertically perforated clay bricks containing microporosities which are produced by addition of pore-maker into the clay raw material.

On the one hand, paper processing waste is used as an additive to an earthenware brick to produce the pores $[13,16]$. Paper production inevitably produces large amounts of waste containing cellulose fibers along with calcium carbonate and clay minerals. This waste contains about 65\% water and is generally dumped on land disposal sites in Turkey. Paper producers are seeking ways to eliminate this waste in an environmentally friendly way. Brick producers use large amounts of natural clayey raw materials for production of earthenware bricks with wide compositional variations. Therefore, these products can tolerate compositional variations due to changes in the raw materials. Hence, in some cases they are capable of incorporating appropriate ratios of waste without significantly losing their product quality [17-19]. Nowadays, increasing global industrial activities brings about the important environmental problems. Specifically, considerable amounts of waste materials are generated from different industrial and agricultural sources [16]. However, these wastes need wide landfills for their disposal, which is difficult to maintain. Also, in developed countries, restricted laws in a form of prohibitions or special taxes for creating waste areas have been implemented. Still stricter waste disposal regulations are expected in the future. For this reason, the utilization or recycling of industrial wastes has been recognized worldwide not only as an economic opportunity but also for solving environmental problems [20-23]. Recently, reuse of wastes from pulp and paper industry in the clay brick materials has especially gained very importance due to their organic and inorganic content [13,18,24-28].

On the other hand, the major variables influencing the thermal conductivity of walls are illustrated in this work by taking different designs of hollow clay bricks made up of paper waste. The finite element method (FEM) is used for finding accurate solutions of the heat transfer equation for clay hollow brick walls. Mathematically, the non-linearity is due to the radiation boundary condition and convection phenomena inside the inner recesses of the bricks [29]. Conduction, convection and radiation phenomena are taking into account in this study for three different hollow clay bricks and four different compositions containing mixtures with paper waste. The development of mathematical models to predict heat transfer processes is a valuable tool in the field of heat and mass transfer technology. These models play an important role in simulation and optimization of complex systems leading to efficient and economical hollow brick designs [30,31].

Furthermore, in order to improve the thermal transmittance of hollow clay bricks the design of experiments (DOE) and response surface methodology (RSM) have been used as modeling tools over the above mentioned finite element models to determine the influence of individual factors and their interactions, using the thermal transmittance as an objective function. The DOE-RSM methodology does not need explicit expressions of the physical meaning of the physical system under study. DOE-RSM models have determined a relationship between the design variables and the output response of the process using a limited number of experimental runs [32,33].

\section{Materials and methods}

\subsection{Brick production for laboratory tests}

In this study, brick clay raw material for brick production obtained from Yüksel Tuğla brick manufacturer (in Turgutlu, Turkey) and recycled paper processing waste for pore making obtained from Levent Kağıt A.Ş. (in Izmir, Turkey) were used. The raw materials were characterized for chemical (X-ray fluorescence analysis), mineralogical (X-ray diffraction analysis), thermal (thermogravimetric analysis) and microstructural (scanning electron microscopy analysis) properties.

For brick production, brick clay and recycled paper waste were initially dried in a drying oven. Then, they were powdered by a disk mill (Fritsch GmbH, Germany). Dewatered paper waste was blended with brick clay in a Heidolph mixer for 30 min (mixing speed, 650-800 rpm). Powder mixture-water ratio of 1:1 was used in the blending process. The resulting mixtures contained up to $30 \%$ by weight of the paper waste. The mixtures were dried, ground and then granulated with sprayed cold water (about $10 \%$ moisture content). The specimens of $85 \mathrm{~mm} \times 85 \mathrm{~mm} \times 10 \mathrm{~mm}$ were uniaxially compacted in a hydraulic press under a pressure of $10 \mathrm{MPa}$ for laboratory tests. The specimens were held overnight at room temperature followed by drying at $45^{\circ} \mathrm{C}$ and then $100^{\circ} \mathrm{C}$ for $2 \mathrm{~h}$ in an oven. Dry specimens were fired in a laboratory-type electrical 
furnace at the rate of $2.5^{\circ} \mathrm{C} / \mathrm{min}$ until $600^{\circ} \mathrm{C}$, and then at the rate of $10^{\circ} \mathrm{C} / \mathrm{min}$ until $1000^{\circ} \mathrm{C}$ for $1 \mathrm{~h}$.

Variations in density and linear shrinkage values were measured using a caliper after drying and firing steps. Archimedes method based on ASTM C20 was used to determine the water absorption, apparent porosity, bulk density and apparent specific gravity of the fired brick samples [34]. Test involves placing in boiling water for $2 \mathrm{~h}$. After boiling kept the specimens immersed in water for a minimum of $12 \mathrm{~h}$ before weighing. The dry weight $\left(W_{d r y}\right)$ of the samples, the suspended weight $\left(W_{\text {suspended }}\right)$ of each sample while suspended in water and then saturated weight ( $\left.W_{\text {saturated }}\right)$ of each sample which has been saturated with water (weight after boiling in water) was determined. The formulas to calculate apparent porosity, water absorption, bulk density and apparent specific gravity of the bricks are as follow:

Apparent porosity, $\%=\frac{\text { open pore volume }}{\text { total volume }} \times 100$

$$
=\frac{W_{\text {saturated }}-W_{\text {dry }}}{W_{\text {saturated }}-W_{\text {suspended }}} \times 100
$$

Water absorption, $\%=\frac{W_{\text {saturated }}-W_{d r y}}{W_{d r y}} \times 100$

Bulk density, $\quad \mathrm{g} / \mathrm{cm}^{3}=\frac{W_{d r y}}{W_{\text {saturated }}-W_{\text {suspended }}}$

Apparent specific gravity, $\mathrm{g} / \mathrm{cm}^{3}=\frac{W_{\text {dry }}}{W_{\text {dry }}-W_{\text {suspended }}}$

The microstructures of fired clay brick samples were determined by scanning electron microscope (SEM). The compressive strengths of fired clay brick samples were measured at a cross head speed of $0.5 \mathrm{~mm} / \mathrm{min}$ in a universal testing machine with a testing capacity of $250 \mathrm{kN}$. The Quick thermal conductivity meter (QTM500, Kyoto Electronics) was used to measure thermal conductivity of the rectangular solid brick samples at room temperature. This equipment which uses the hot wire method was used in the measurement of thermal conductivity because it is a fast and accurate method for measurement of thermal conductivity of insulating brick materials. It involves placing the rectangular brick sample $(85 \mathrm{~mm} \times 85 \mathrm{~mm} \times 10 \mathrm{~mm})$ in the probe box and then placing the sensor probe (PD-11) on the sample surface. The sensor probe consists of a wire heater and thermocouple. The heating wire is used to supply heat to the sample and the thermocouple monitors the heat flow rate. The measurement result is shown on display immediately after the measurement is finished. The measured values are the thermal conductivities of solid brick materials.

\subsection{Numerical modeling as vertically multi-holed bricks designed of the produced samples}

Based on previous research works [29-31,35,36], we have used the finite element method (FEM) as a tool for the theoretical investigation of the thermal behavior of three different multi-holed bricks under steady-state conditions. Usually, brick recesses are too long in comparison to their transversal dimensions and, in consequence, a two-dimensional approach is adopted in the subsequent numerical FEM models. A wall composed of five bricks is modeled and only the central brick is used to obtain the thermal parameters, in order to avoid the border effect in the temperature distribution.

Furthermore, based on the FEM models, the design of experiments and response surface methodology (DOE-RSM) are used to study the influence of different parameters on the thermal performance and optimize the thermal behavior of bricks. The configuration of recesses (size and number), the surface emissivity (in the central hole and the rest), the material thermal conductivity

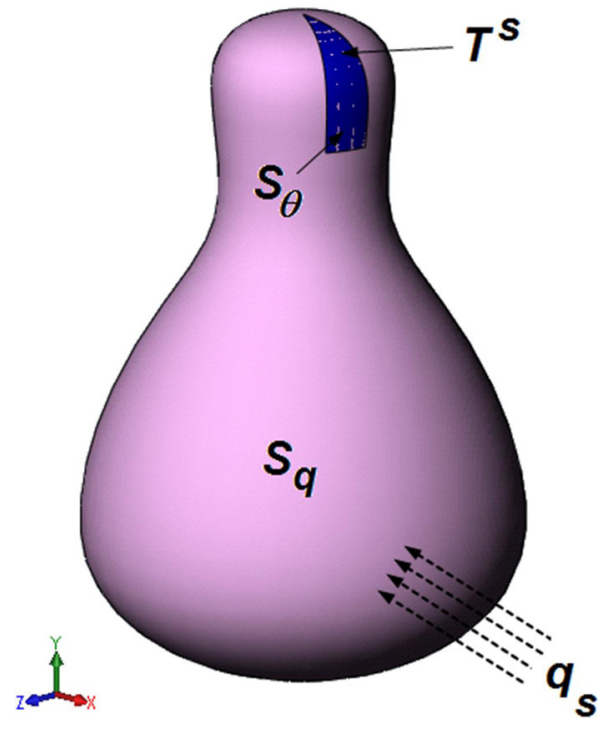

Fig. 1. Body subjected to heat transfer.

and the mean temperature for the black body radiation coefficient are the main parameters considered in this research.

\subsubsection{Description of mathematical model}

In the study of finite element analysis of heat transfer problems it is important to describe the differential and variational equations that govern the heat transfer conditions to be analyzed [36,37]. These equations provide the basis for the finite element method (FEM) of the heat transfer problems.

2.2.1.1. Governing classical heat transfer equations. Considering a three dimensional body in steady state heat transfer conditions as it is shown in Fig. 1. For the heat transfer analysis we assume that the material obeys Fourier's law of heat conduction [38]:

$q_{x}=-\lambda_{x} \frac{\partial T_{m}}{\partial x} ; \quad q_{y}=-\lambda_{y} \frac{\partial T_{m}}{\partial y} ; \quad q_{z}=-\lambda_{z} \frac{\partial T_{m}}{\partial z}$

where $q_{x}, q_{y}$ and $q_{z}$ are the heat flows conducted per unit area, $T_{m}$ is the temperature of the body, and $\lambda_{x}, \lambda_{y}$ and $\lambda_{z}$ are the thermal conductivities corresponding to the principal axes $x, y$ and $z$. Considering the equilibrium of the heat flow, due to the steadystate condition, in the interior of the body, we obtain [39]:

$\frac{\partial}{\partial x}\left(\lambda_{x} \frac{\partial T_{m}}{\partial x}\right)+\frac{\partial}{\partial y}\left(\lambda_{y} \frac{\partial T_{m}}{\partial y}\right)+\frac{\partial}{\partial z}\left(\lambda_{z} \frac{\partial T_{m}}{\partial z}\right)=-q^{B}$

where $q^{B}$ is the rate of heat generated per unit volume. On the surfaces of the body the following conditions must be satisfied [38]:

$\left.T_{m}\right|_{S_{T}}=T^{S}$

$\left.\lambda_{n} \frac{\partial T_{m}}{\partial n}\right|_{S_{q}}=q^{S}$

where $T^{S}$ is the known surface temperature on $S_{T}, \lambda_{n}$ is the material thermal conductivity, $n$ denotes the coordinate axis in the direction of the unit normal vector $\vec{n}$ (pointing outward) to the surface, $q^{S}$ is the prescribed heat flux input on the surface $S_{q}$ of the body, and $S_{T} \cup S_{q}=S, S_{T} \cap S_{q}=0$.

A number of important assumptions apply to the use of Eqs. (5)-(8). The first assumption considered is the heat conduction conditions in solids and structures (material particles of the body are at rest). The second assumption is that the heat transfer and the 
stress conditions can be analyzed decoupled. The final assumption is that there are no phase changes and latent heat effects.

2.2.1.2. Boundary conditions. Different boundary conditions are encountered in heat transfer analysis:

- Temperature conditionsThe temperature may be prescribed at specific points and surface of the body, denoted by $S_{T}$ in Eq. (7).

- Heat flow conditionsThe heat flow input may be prescribed at specific points and surfaces of the body. These heat flow boundary conditions are specified in Eq. (8).

- Convection boundary conditionsIncluded in Eq. (8) are convection boundary conditions where [38,39]:

$q^{S}=h_{a}\left(T-T^{S}\right)$

where $h_{a}$ is the convection coefficient. In our problem, the ambient temperature $T$ is known, but the surface temperature $T^{S}$ is unknown.

- Radiation boundary conditionsRadiation boundary condition is also specified in (8) with [39]:

$q^{S}=h_{r}\left(T_{r}-T^{S}\right)$

where $T_{r}$ is the known temperature of the external radiative source and $h_{r}$ is a radiation film coefficient, evaluated using absolute temperatures, according to the UNE-EN-ISO 6946 standard rule [40].

$$
\begin{aligned}
h_{r} & =h_{r 0}\left[\left(T_{r}\right)^{2}+\left(T^{S}\right)^{2}\right]\left(T_{r}+T^{S}\right) \\
& =\frac{1}{2} E \cdot h_{r 0} \cdot\left(1+\sqrt{1+\frac{t^{2}}{w^{2}}}-\frac{t}{w}\right)
\end{aligned}
$$

The variable $h_{r 0}$, radiation coefficient for a black body, is calculated from the Stefan-Boltzmann constant, the emissivity of the radiant and absorbing materials, and the geometric view factors.

2.2.1.3. Variational formulation of the general heat transfer equation. For the finite element solution of the heat transfer problem we use the principle of virtual temperatures given as [38,39]:

$\int_{V} \bar{T}_{m}^{\prime}{ }_{m}^{T} \lambda T_{m}^{\prime} d V=\int_{V} \bar{T}_{m} q^{B} d V+\int_{S_{q}} \bar{T}^{S} q^{S} d S+\sum_{i} \bar{T}_{m_{i}} Q^{i}$

where

$T_{m}^{\prime T}=\left[\frac{\partial T_{m}}{\partial x} \frac{\partial T_{m}}{\partial y} \frac{\partial T_{m}}{\partial z}\right]$

$\lambda=\left[\begin{array}{ccc}\lambda_{x} & 0 & 0 \\ 0 & \lambda_{y} & 0 \\ 0 & 0 & \lambda_{z}\end{array}\right]$

and the $Q^{i}$ are concentrated heat flow inputs. Each $Q^{i}$ is equivalent to a surface heat flow input over a very small discretised area (the finite element surface). The bar over the temperature $T$ indicates that a virtual temperature distribution is being considered.

The principle of virtual temperatures is an equation of heat flow equilibrium: for $T_{m}$ to be the solution of the temperature in the body under consideration, Eq. (12) must hold for arbitrary virtual (continuous) temperature distributions that are zero on $S_{\theta}$. In summary, it is an equation corresponding to the condition of stationarity of the following functional $[38,39]$ :

$$
\begin{aligned}
\Pi= & \int_{V} \frac{1}{2}\left[\lambda_{x}\left(\frac{\partial T_{m}}{\partial x}\right)^{2}+\lambda_{y}\left(\frac{\partial T_{m}}{\partial y}\right)^{2}+\lambda_{z}\left(\frac{\partial T_{m}}{\partial z}\right)^{2}\right] d V \\
& -\int_{V} T_{m} q^{B} d V-\int_{S_{q}} T_{m} q^{S} d S-\sum_{i} T_{m}^{i} Q^{i}
\end{aligned}
$$

Namely, invoking $\delta \Pi=0$, we obtain [39]:

$\int_{V} \delta T_{m}^{\prime} \lambda T_{m}^{\prime} d V=\int_{V} \delta T_{m} q^{B} d V+\int_{S_{q}} \delta T^{S} q^{S} d S+\sum_{i} \delta T_{m}^{i} Q^{i}$

where $\delta T_{m}$ can be arbitrary but must be zero on $S_{\theta}$. Using integration by parts on Eq. (16) we can extract the governing differential equation of equilibrium (Eq. (6)) and the heat flow boundary condition Eq. (8). However, on comparing Eqs. (16) with (1), we recognize that Eq. (16) is the principle of virtual temperatures with $\delta T_{m} \equiv \bar{T}_{m}$.

\subsubsection{FEM modeling}

In order to study the thermal performance of this material for their use in construction facades, we have modeled walls composed of three different brick models (see Fig. 2).

The first brick, B1, has $0.3 \mathrm{~m}$ length and $0.19 \mathrm{~m}$ width, the second brick, B2, has $0.265 \mathrm{~m}$ length and $0.24 \mathrm{~m}$ width and the third brick, B3, has $0.27 \mathrm{~m}$ length and $0.26 \mathrm{~m}$ width. Cavities are different depending on the kind and size of brick, and the distribution and main dimensions are indicated in Fig. 2. Therefore, due to the different number, shape, distribution and length of recesses the thermal performance properties are clearly different in each brick.

In this study, we try to analyze the influence of several parameters such as the material conductivity, the convection and radiation properties and the geometry of the recesses in the thermal performance of walls made up of different bricks. The main goal of this study is to optimize the thermal behavior of the brick and select the best candidate and material properties with respect to the paper waste addition.

Size and shape thermal optimization problems are usually stated in terms of a minimum weight with temperature constraint approach. These traditional minimum compliance statements for topology optimization problems offer some obvious advantages, since it is prevented to deal with a large number of highly non-linear temperature constraints.

In this section we will describe the finite element modeling and analysis techniques used, taking into account the excellent agreement between experimental tests and numerical simulations by FEM for a certain wall's configuration [30,31].

For modeling of clay bricks lightened with paper waste, we used a plane element with four nodes, named PLANE55 [41,42]. This is a four-node element with a one degree of freedom (temperature) per node, well suited to model curved boundaries, such as recesses and faces of the bricks. The element is also appropriate to reproduce the behavior of heat transference for conduction in the solid.

To simulate the convection and radiation phenomena in the brick inner recesses, we used surface elements with 3 nodes, 2 nodes +1 extra node included, named SURF151 [42], which has one degree of freedom (temperature) per node.

\subsubsection{Thermal loads and boundary conditions}

To analyze the thermal behavior in the models studied in this research, the following boundary conditions are considered:

- Horizontal heat flow $q$ equal to $10 \mathrm{~W} / \mathrm{m}^{2}$ in one side of the wall.

- External film coefficient of $25 \mathrm{~W} / \mathrm{m}^{2} \mathrm{~K}$, corresponding to an exterior wall face.

- Ambient temperature of $295 \mathrm{~K}$. 

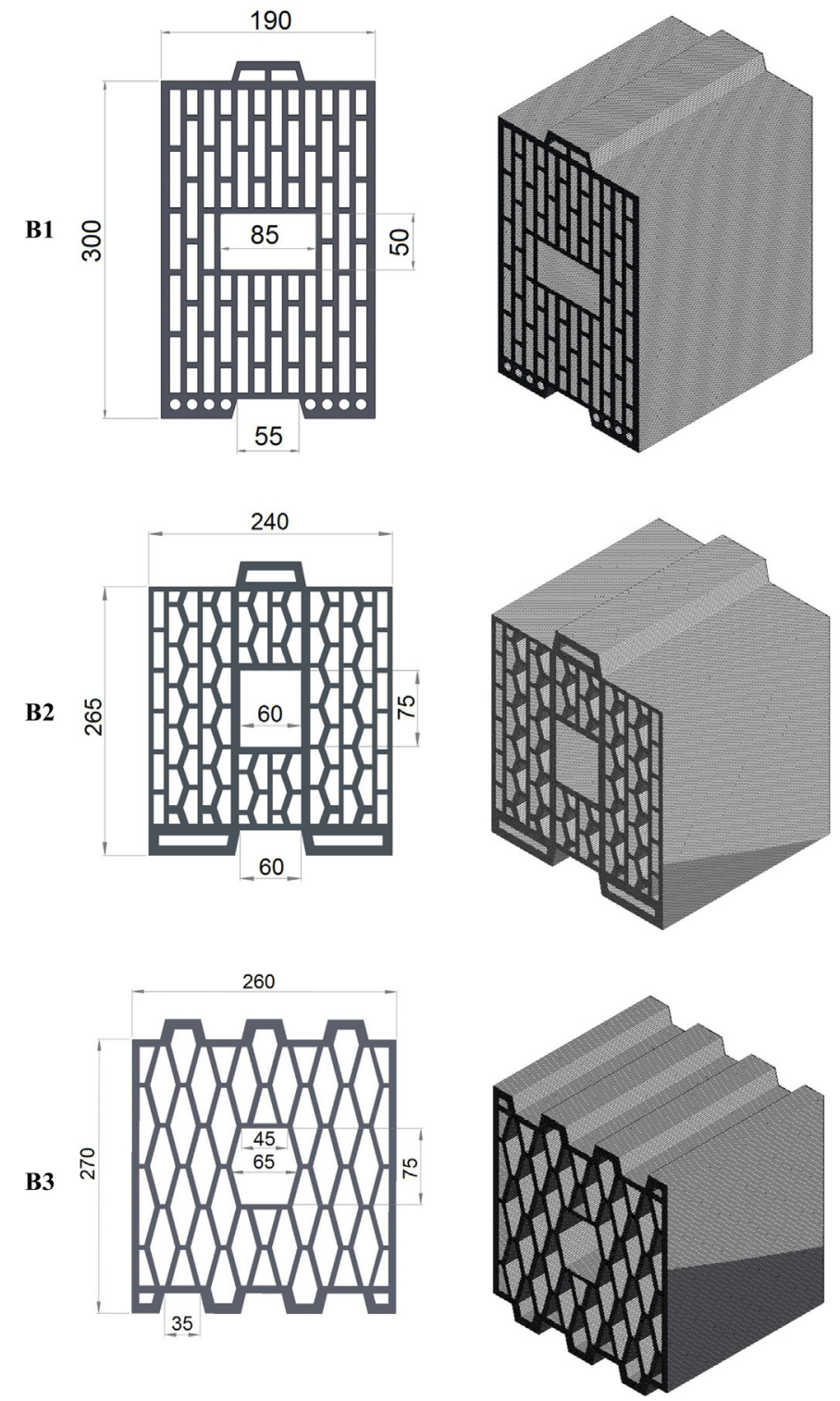

Fig. 2. Dimensions of brick models (B1, B2 and B3) designed for this study (in mm).

We have implemented the nonlinear radiation and convection phenomena inside recesses using the procedure indicated in Annex $B$ from the UNE-EN-ISO 6946 standard rule [40]. The film coefficient of a specific hole in which the length is less than ten times their thickness is calculated from the following equation:

$h_{t o t}=h_{a}+\frac{1}{2} E \cdot h_{r 0} \cdot\left(1+\sqrt{1+\frac{t^{2}}{w^{2}}}-\frac{t}{w}\right)$

The problem was solved in a workstation computer with a double-CPU Intel Xeon 5140 @ $2.33 \mathrm{GHz}, 24 \mathrm{~GB}$ RAM memory and 4.0 TB hard disk. The total elapsed average CPU time per case was $500 \mathrm{~s}$ and the total number of iterations in order to get the convergence about 50 .

\subsubsection{Predictive modeling using DOE-RSM}

Firstly, the design of experiments and response surface methodology (DOE-RSM) techniques are an optimization approach that allows the calculation of the input variables that maximize or minimize a specific objective function [32]. Based on these techniques (DOE-RSM) the second order polynomial regression models can be developed to predict the performance of any physical system. During the DOE-RSM modeling the input variables $x_{1}, x_{2}, \ldots, x_{n}$ must be scaled to coded levels. In coded scale the factors varies from a minimum level $(-1)$ up to a maximum level $(+1)$. The second-order models given by RSM are often used to determine the critical points (maximum, minimum, or saddle) and can be written in a general form as [33]:

$\widehat{Y}=\beta_{0}+\sum_{i=1}^{n} \beta_{i} x_{i}+\sum_{i=1}^{n} \beta_{i i} x_{i}^{2}+\sum_{i<j}^{n} \beta_{i j} x_{i} x_{j}$

where $\widehat{Y}$ denotes the predicted response, $x_{i}$ refers to the coded levels of the input variables, $\beta_{0}, \beta_{i}, \beta_{i i}, \beta_{i j}$ are the regression coefficients (offset term, main, quadratic and interaction effects) and $\mathrm{n}$ is the total number of variables. To determine the regression coefficients, the ordinary least squares (OLS) method is used. The OLS estimator can be written as follows [32,33]:

$\vec{\beta}_{\text {OLS }}=\left(\vec{X}^{T} \vec{X}\right)^{-1} \vec{X}^{T} \vec{Y}$

where $\beta_{O L S}$ is a vector of regression coefficients, $\vec{X}$ is an extended designed matrix of the coded levels of the input variables, $\vec{Y}$ is a column vector of response determined according to the arrangements points into the experimental design.

Secondly, an enhanced central composite design (ECCD) was selected for the optimization of the most important parameters in the design of experiments (DOE) methodology [32,33]. In this way, the following parameters and range of variation have been considered in all FEM models (see Table 2):

- Surface emissivity in all recesses, excluding central hole, from 0.75 to 0.99

- Surface emissivity in central hole, from 0.75 to 0.99

- Thermal conductivity, from 0.39 to $0.68 \mathrm{~W} / \mathrm{m} \mathrm{K}$

- Mean temperature for the black body radiation coefficient, from 260 to $303 \mathrm{~K}$

Taking into account the above mentioned input variables, each ECCD must solve fifty different FEM models for each brick type, giving place to 150 different analyses for all cases.

\section{Results and discussion}

\subsection{Characterization of raw materials}

Physical, mineralogical, microstructural and thermal properties of the raw materials are presented in a previous publication of the authors [13]. The chemical composition of the clay consisted of $61.7 \% \mathrm{SiO}_{2}, 15.7 \% \mathrm{Al}_{2} \mathrm{O}_{3}, 0.8 \% \mathrm{TiO}_{2}, 6.8 \% \mathrm{Fe}_{2} \mathrm{O}_{3}, 2.4 \% \mathrm{~K}_{2} \mathrm{O}, 2.1 \% \mathrm{CaO}$, $2.3 \% \mathrm{MgO}$ and $0.3 \% \mathrm{Na}_{2} \mathrm{O}$. According to X-ray fluorescence (XRF) analysis, paper waste includes $6.4 \% \mathrm{SiO}_{2}, 4.1 \% \mathrm{Al}_{2} \mathrm{O}_{3}, 0.1 \% \mathrm{TiO}_{2}$, $0.3 \% \mathrm{Fe}_{2} \mathrm{O}_{3}, 0.1 \% \mathrm{~K}_{2} \mathrm{O}, 32.9 \% \mathrm{CaO}, 1.5 \% \mathrm{MgO}$ and $0.1 \% \mathrm{Na}_{2} \mathrm{O}$. Loss on ignition of brick clay and paper waste upon heating at $1000{ }^{\circ} \mathrm{C}$ was measured as 7.5 and $53.8 \%$, respectively. The mineral phases in brick clay contained high amount of quartz and clay minerals such as illite and chlorites; and paper waste included mainly calcium carbonate, cellulose and less amount of clay minerals [13].

The firing steps of brick samples were planned according to thermo-gravimetric analysis results. The TGA curve of the paper waste is given in Fig. 3. The analysis followed the burning of cellulose fibers $(\sim 30 \%)$ around $350^{\circ} \mathrm{C}$ and the decomposition of calcium carbonate $(\sim 20 \%)$ above $700{ }^{\circ} \mathrm{C}$. The TG analysis of the paper waste showed that these waste contained about $30 \%$ organic (cellulose fibers) and 70\% inorganic components like calcite and other clayey materials. According to the TGA curve, loss on ignition of paper waste is about $54 \%$. 
Table 1

Experimental results of the fired samples.

\begin{tabular}{|c|c|c|c|c|}
\hline \multirow[t]{2}{*}{ Physical properties } & \multicolumn{4}{|c|}{ Mass ratio of paper waste addition } \\
\hline & $0 \%$ & $10 \%$ & $20 \%$ & $30 \%$ \\
\hline Loss on ignition (\%) & 7.5 & 13.0 & 17.4 & 22.3 \\
\hline Apparent porosity (\%) & $31.7 \pm 0.8$ & $40.7 \pm 0.9$ & $46.7 \pm 0.5$ & $50.7 \pm 0.7$ \\
\hline Water absorption (\%) & $17.2 \pm 0.7$ & $25.6 \pm 0.9$ & $32.8 \pm 0.8$ & $38.4 \pm 1.0$ \\
\hline Bulk density $\left(\mathrm{g} / \mathrm{cm}^{3}\right)$ & $1.85 \pm 0.03$ & $1.59 \pm 0.02$ & $1.42 \pm 0.02$ & $1.32 \pm 0.02$ \\
\hline Apparent specific gravity $\left(\mathrm{g} / \mathrm{cm}^{3}\right)$ & $2.70 \pm 0.01$ & $2.68 \pm 0.00$ & $2.67 \pm 0.01$ & $2.68 \pm 0.01$ \\
\hline Thermal conductivity $(\mathrm{W} / \mathrm{m} \mathrm{K})$ & $0.68 \pm 0.01$ & $0.50 \pm 0.005$ & $0.46 \pm 0.004$ & $0.39 \pm 0.003$ \\
\hline Compressive strength (MPa) & $31.1 \pm 2.0$ & $12.6 \pm 0.7$ & $13.1 \pm 0.9$ & $7.0 \pm 0.8$ \\
\hline
\end{tabular}

In Fig. 4a and b, microstructural images of short cellulose fibers and finely inorganic particles in the paper waste used as pore-making additive for porous brick production are shown, respectively. Thicknesses of the cellulose fibers are smaller than $20 \mu \mathrm{m}$. Inorganic particles containing mainly calcium carbonate in the waste were observed to be quite fine particles.

\subsection{Characterization of the fired brick samples}

Recycled paper waste of up to $30 \mathrm{wt} \%$ was used in making fired brick. It was observed that the color of the brick got lighter shades of red with increasing amount of waste additions due to the presence of higher amounts of calcium. Experimental results of the sam-

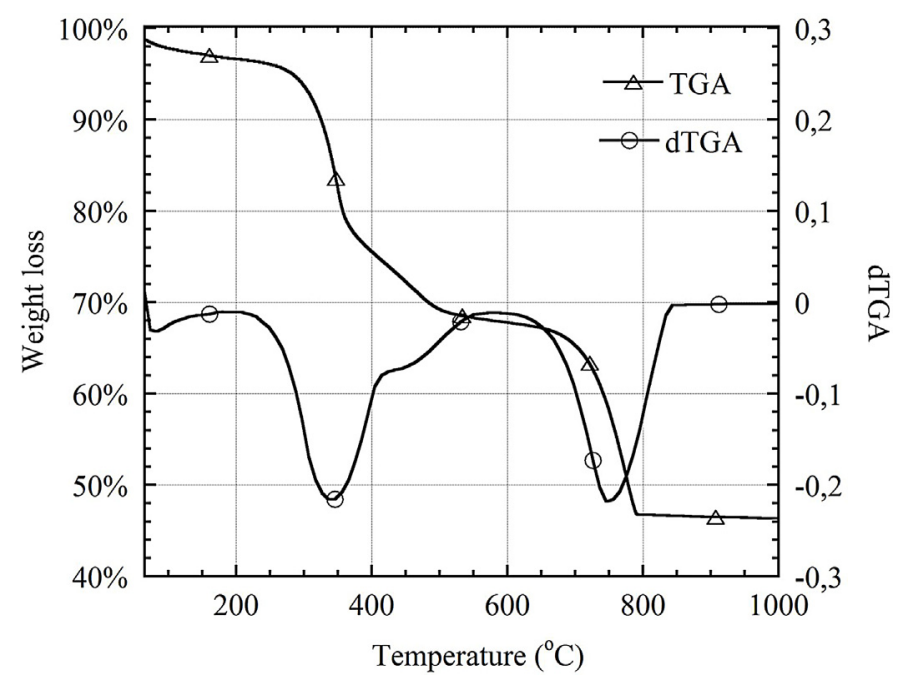

Fig. 3. TGA curves of paper waste.

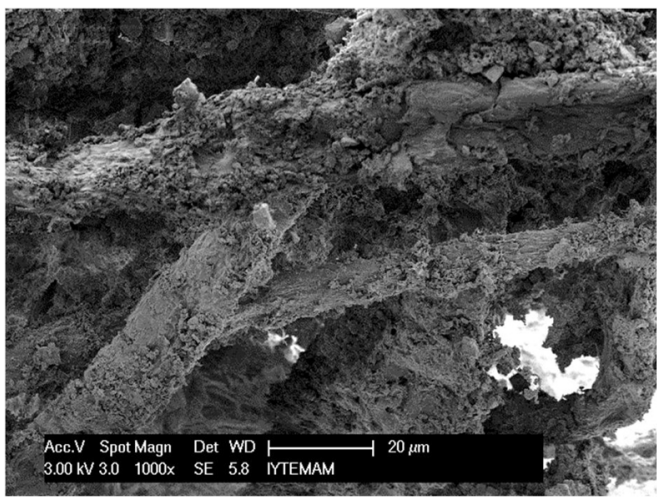

(a) ples fired at $1000^{\circ} \mathrm{C}$ are given in Table 1. Drying shrinkage values of the bricks varied between 1 and 2\% due to the less moisture content. Bulk density, apparent specific gravity, apparent porosity and water absorption values of the samples were measured by the Archimedes' principle using boiling water [18]. The results obtained revealed that bulk densities decreased steadily with an increase in the amount of the paper waste. Bulk density of the fired bricks decreased from 1.85 to $1.32 \mathrm{~g} / \mathrm{cm}^{3}$, which corresponds to a decrease by up to $30 \%$ compared to density of the brick without paper waste. Apparent porosity values of the samples were measured between $31.7 \%$ and $50.7 \%$ with increasing waste addition while the bulk densities were significantly reduced. Also, their water absorption values increased depending on the mass ratio of waste addition.

The thermal conductivity values of the brick samples measured based on hot-wire method at ambient conditions are given in Table 1 . The thermal conductivity of the samples decreased considerably by increasing paper waste content. The paper waste addition into the bricks decreased the density of brick samples after firing. Thermal conductivity of the bricks depends on their firing temperatures, densities and therefore porosities [18]. Thermal conductivity of the porous brick with $30 \%$ paper waste $(0.39 \mathrm{~W} / \mathrm{m} \mathrm{K})$ showed a reduction of $43 \%$ according to the brick without paper waste $(0.68 \mathrm{~W} / \mathrm{m} \mathrm{K})$. This reduction in thermal conductivity of the material is encouraging for higher energy saving potential in building applications. The compressive strengths of fired clay brick samples were measured and the results obtained are given in Table 1. Paper waste addition and the resulting porosity decreased the compressive strength of the brick samples which were still higher than the minimum standard strength values of $7 \mathrm{MPa}$ [43]. The compressive strength of vertically perforated bricks ( $40 \%$ of cavity) varies between 4 and $20 \mathrm{MPa}$ depending on their densities $\left(<1000 \mathrm{~kg} / \mathrm{m}^{3}\right)$ [8].

In addition, microstructure of the brick samples was investigated using scanning electron microscope (SEM). Fig. 5 shows the

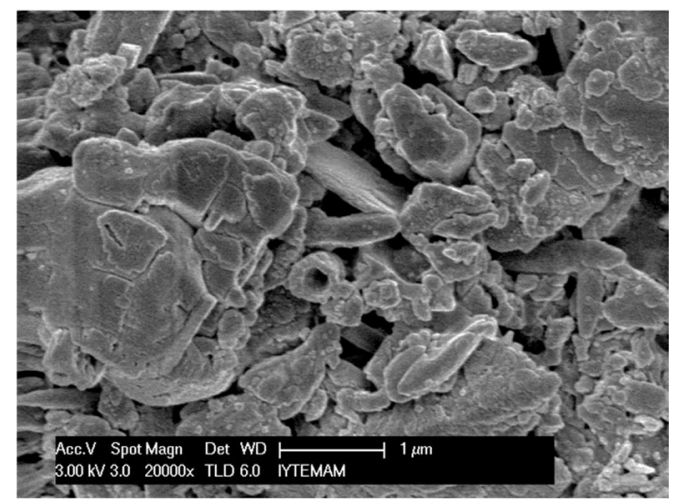

(b)

Fig. 4. SEM images of the recycled paper waste used as pore-making additive. 


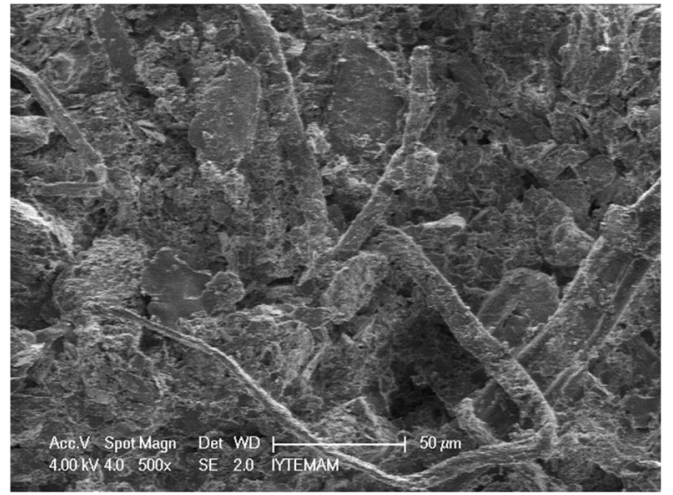

(a)

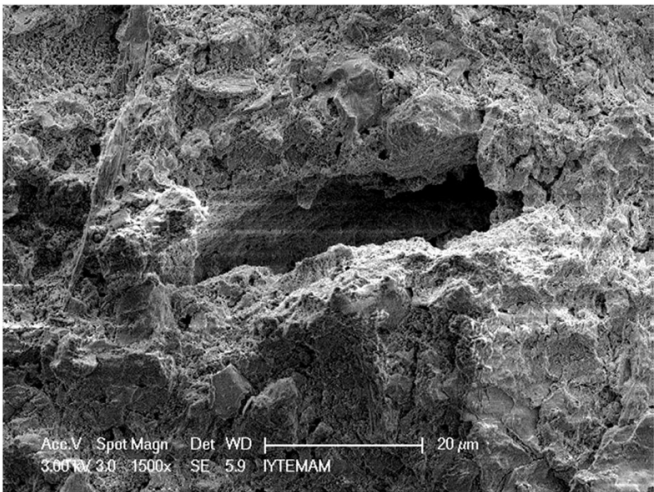

(b)

Fig. 5. SEM images of the fracture surfaces of (a) unfired and (b) fired brick samples produced with $30 \%$ paper waste.

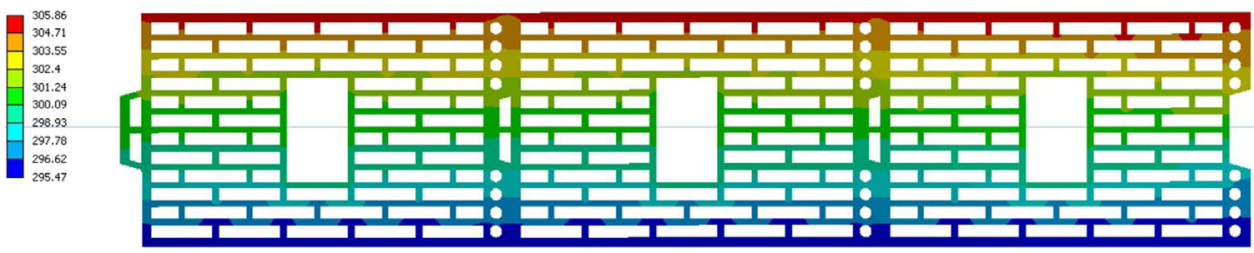

(a) type B1

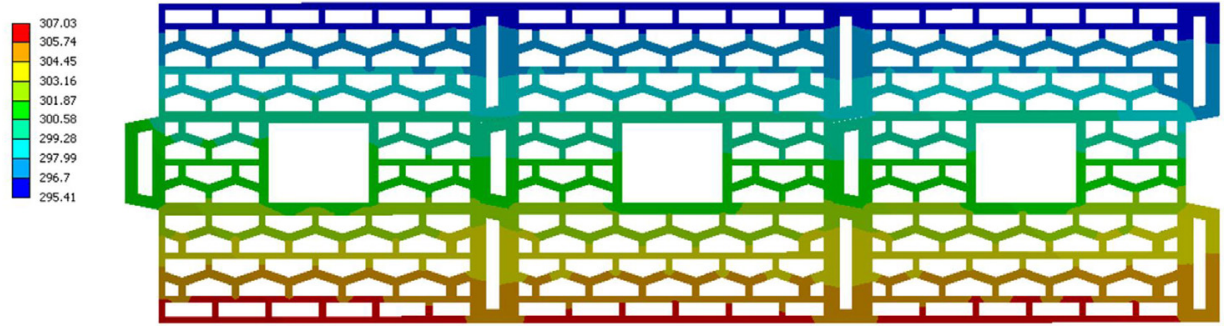

(b) type B2

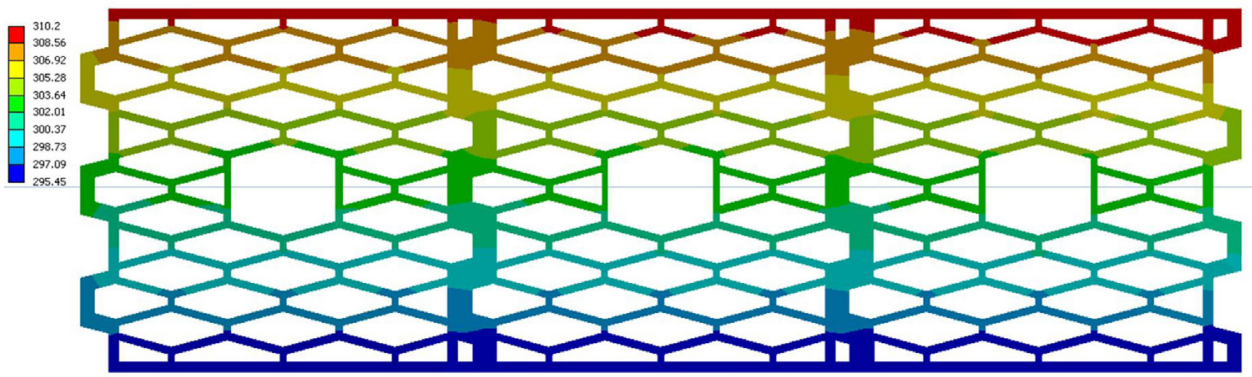

(c) type B3

Fig. 6. Temperature distribution in walls made up of bricks.

Table 2

Numerical results of the bricks.

\begin{tabular}{|c|c|c|c|c|c|c|c|}
\hline Brick & Case & $\lambda(\mathrm{W} / \mathrm{m} \mathrm{K})$ & $T_{\text {black }}(\mathrm{K})$ & $\varepsilon$ & $\varepsilon_{\text {hole }}$ & $U_{1}\left(\mathrm{~W} / \mathrm{m}^{2} \mathrm{~K}\right)$ & $U_{2}\left(\mathrm{~W} / \mathrm{m}^{2} \mathrm{~K}\right)$ \\
\hline B1 & Best & 0.39 & 260 & 0.75 & 0.75 & 0.704 & 0.768 \\
\hline B2 & Best & 0.39 & 260 & 0.75 & 0.75 & 0.652 & 0.734 \\
\hline B3 & Best & 0.39 & 260 & 0.75 & 0.75 & 0.473 & 0.507 \\
\hline B1 & Medium & 0.535 & 281.5 & 0.87 & 0.81 & 0.926 & 1.014 \\
\hline B2 & Medium & 0.535 & 281.5 & 0.87 & 0.81 & 0.847 & 0.958 \\
\hline B3 & Medium & 0.535 & 281.5 & 0.87 & 0.75 & 0.646 & 0.696 \\
\hline B1 & Worst & 0.68 & 303 & 0.99 & 0.99 & 1.213 & 1.328 \\
\hline B2 & Worst & 0.68 & 303 & 0.99 & 0.99 & 1.083 & 1.226 \\
\hline B3 & Worst & 0.68 & 303 & 0.99 & 0.99 & 0.863 & 0.931 \\
\hline
\end{tabular}




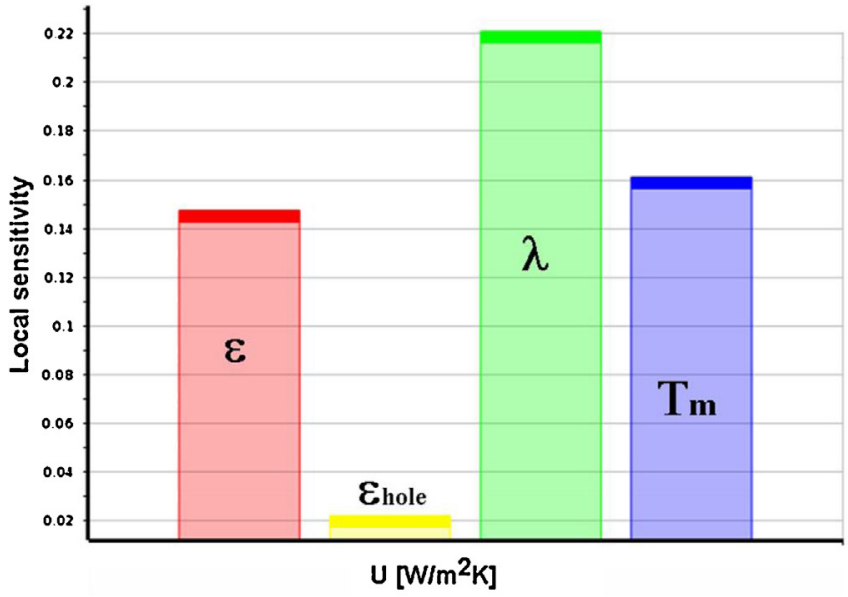

(a)

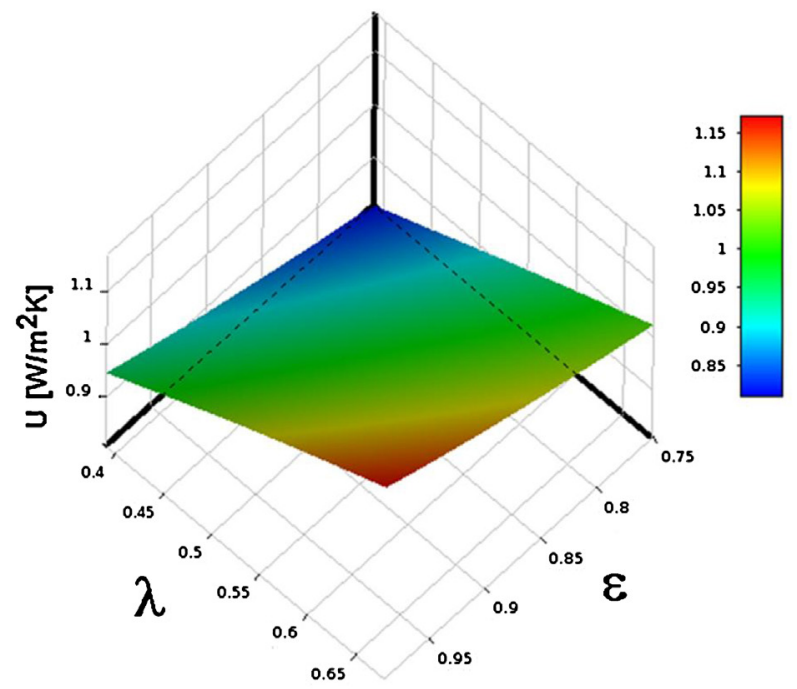

(c)

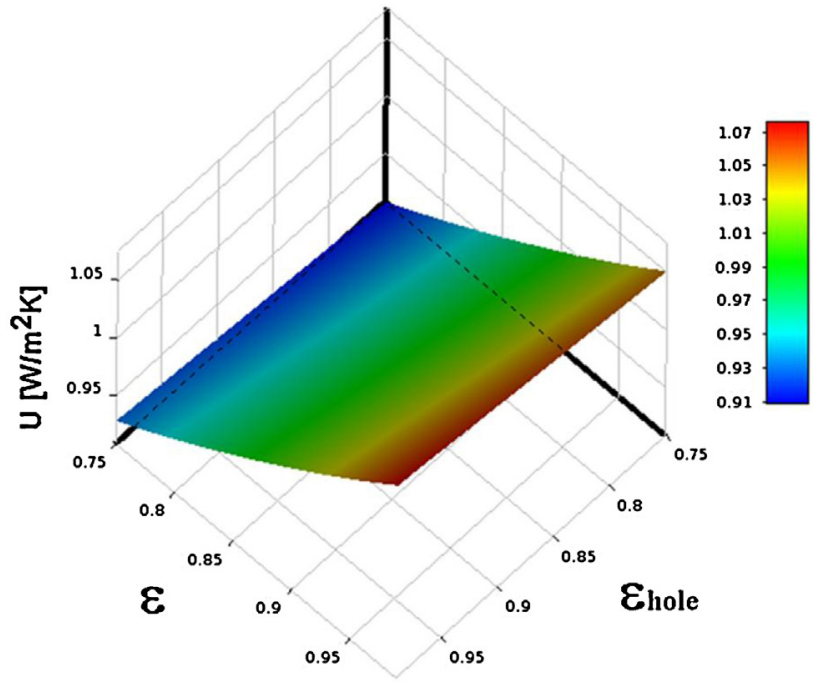

(b)

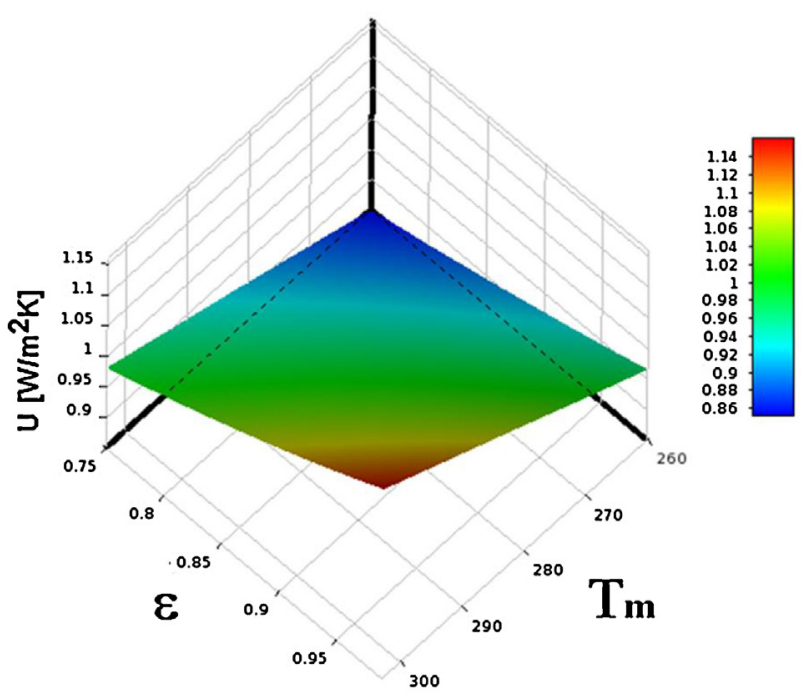

(d)

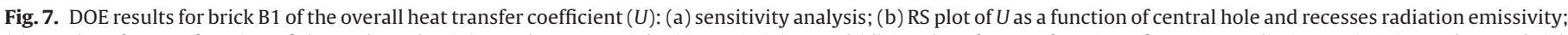

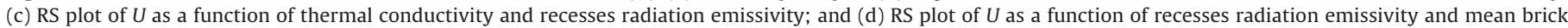
temperature.

SEM images of the fracture surfaces of unfired and fired brick samples produced with $30 \%$ paper waste. This microstructure revealed that cellulose fibers were immersed in the green brick body. Thicknesses of the fibers varied from 5 to $20 \mu \mathrm{m}$. During firing, these cellulose fibers burned and vacant holes were formed in their locations inside the brick body (Fig. 5b). Also, micro-pores occurred due to the decomposition of calcium carbonate. In general, calcium carbonate is used as pore forming agent in the manufacture of porous materials. Both the cellulose fibers and calcite helped to form the porosity in this study. Coarse particles observed in the structure were identified as quartz by energy dispersive X-ray spectroscopy analysis (EDS). In fired samples, the microstructure of the samples with paper waste also consisted calcium-rich aluminum silicate phases due to the sintering reaction of calcite and clay minerals $[13,18]$.

\subsection{Numerical results and discussion}

\subsubsection{Numerical FEM results}

The results obtained using FEM $[6,9,30,31]$ are processed in order to obtain the overall heat transfer coefficient, $U\left(\mathrm{~W} / \mathrm{m}^{2} \mathrm{~K}\right)$. The calculation of this parameter is based on the next equations $[44,45]$ :

$U=\frac{q / A}{\Delta T_{m}}$

Due to the small variations of temperature in each face of the brick, the maximum $\left(U_{2}\right)$ and mean $\left(U_{1}\right)$ values of the heat transfer coefficient over the central brick are used to obtain the characteristic thermal transmittance value using the Eq. (20). Furthermore, from the 150 different FEM models calculated as design points in 


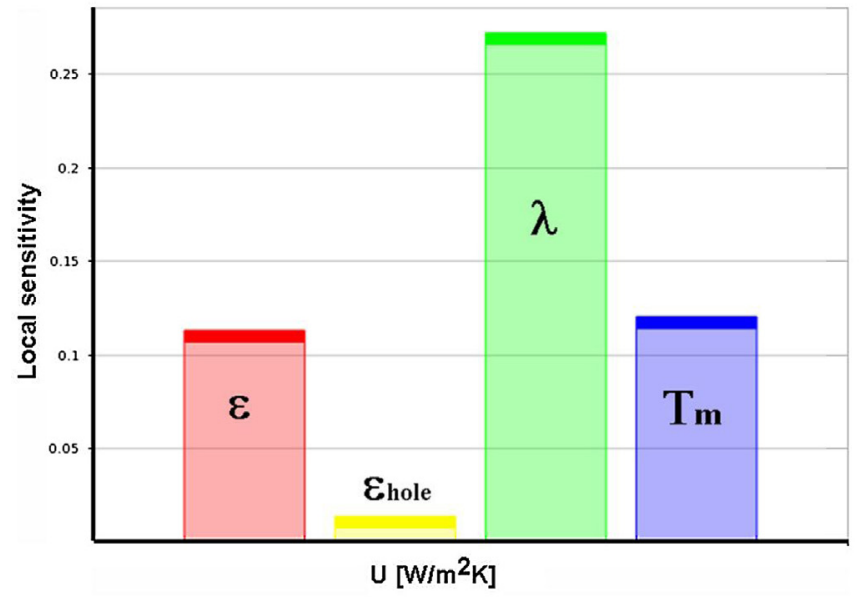

(a)

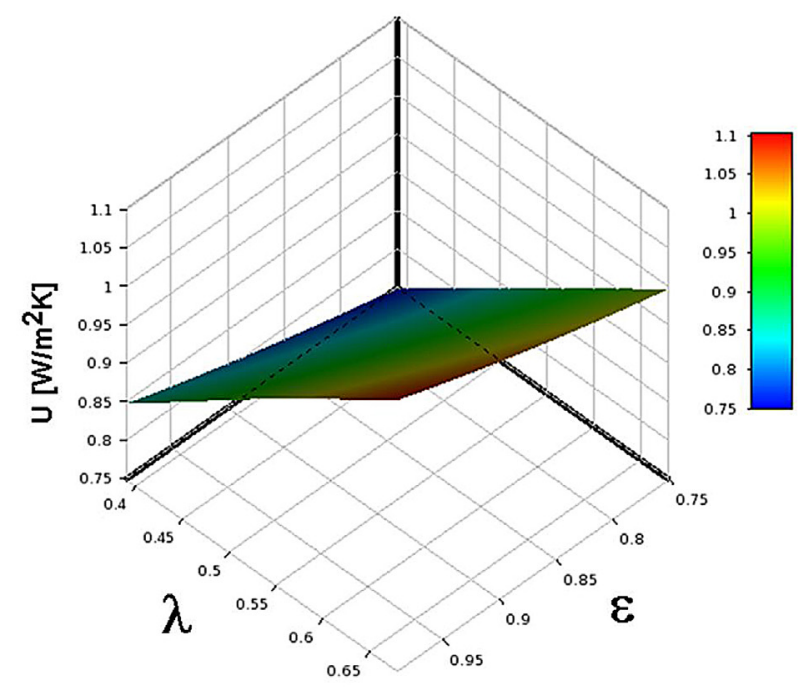

(c)

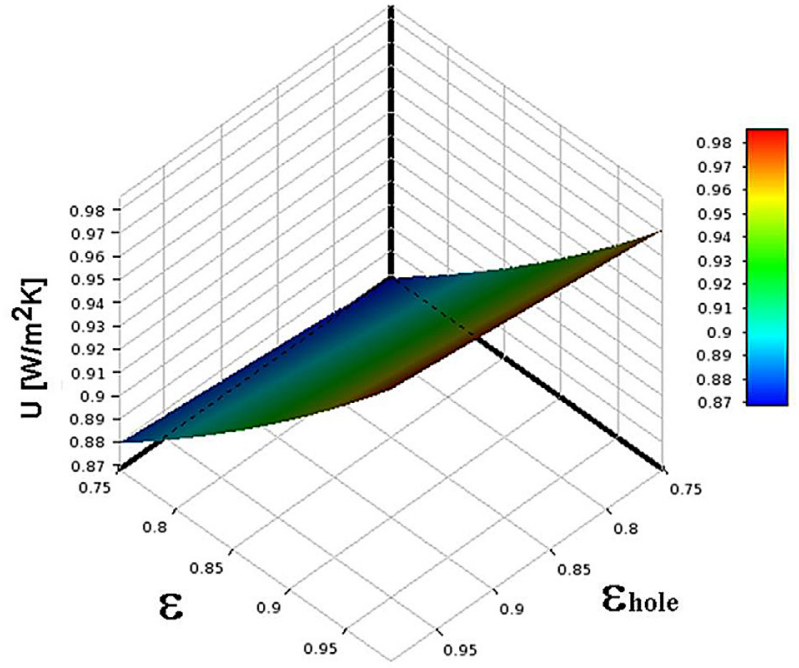

(b)

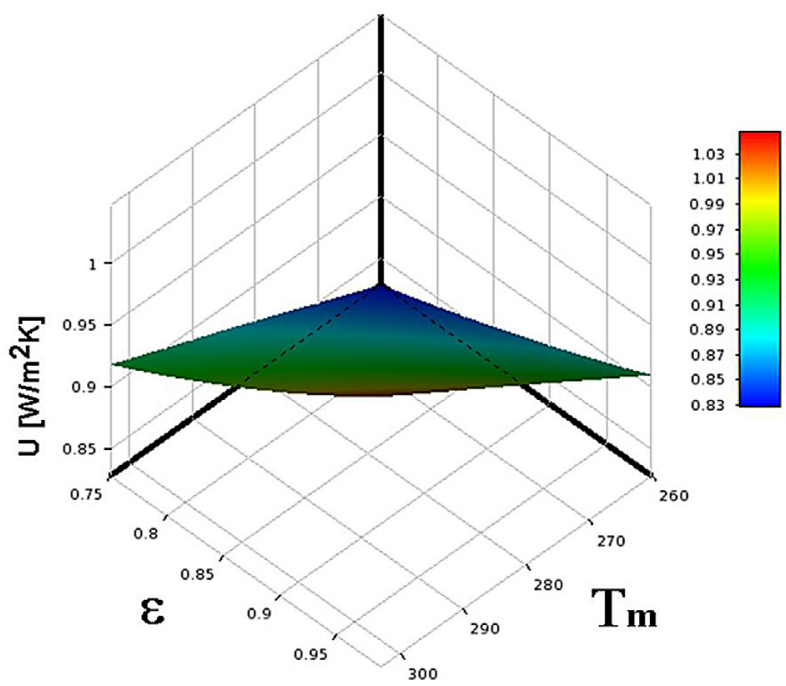

(d)

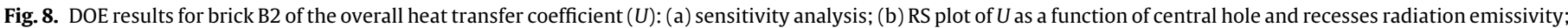

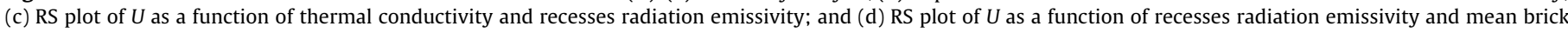
temperature.

the DOE method, the main numerical results are provided in Table 2. In this table, the best, worst and medium case with respect to the heat transfer coefficient is indicated for each brick. The values of the parameters corresponding to each case are also provided, in order to understand the main effect of each one of them in the thermal performance of bricks, specifically:

- The surface emissivity value in all recesses, excluding central hole, $\varepsilon$

- The surface emissivity in central hole, $\varepsilon_{\text {hole }}$

- The material thermal conductivity, $\lambda \mathrm{W} / \mathrm{m} \mathrm{K}$

- The mean temperature for the black body radiation coefficient, $T_{\text {black}}$,

Results reveal the following main findings:

- In all analyzed cases, a decrease of the recesses' surface radiation emissivity causes a lower thermal transmittance in the brick.
- In general, a decrease of the material thermal conductivity implies a better thermal behavior.

- The mean temperature for the black body radiation coefficient play an important role in the thermal transmittance of this type of bricks: lower temperature implies better thermal transmittance.

- The most efficient candidate is the brick B3, followed by the B2 and the B1.

Fig. 6 shows the temperature distribution corresponding to walls made up of bricks B1, B2 and B3. After examining the numerical results it can be assumed that the simulation by FEM constitutes a reasonable approach to describe the thermal behavior of the system according to other previous research works [30,31]. In summary, the FE model may reproduce quite accurately the heat transfer in complex walls with multiple recesses, made up of clay and paper waste mixtures. 


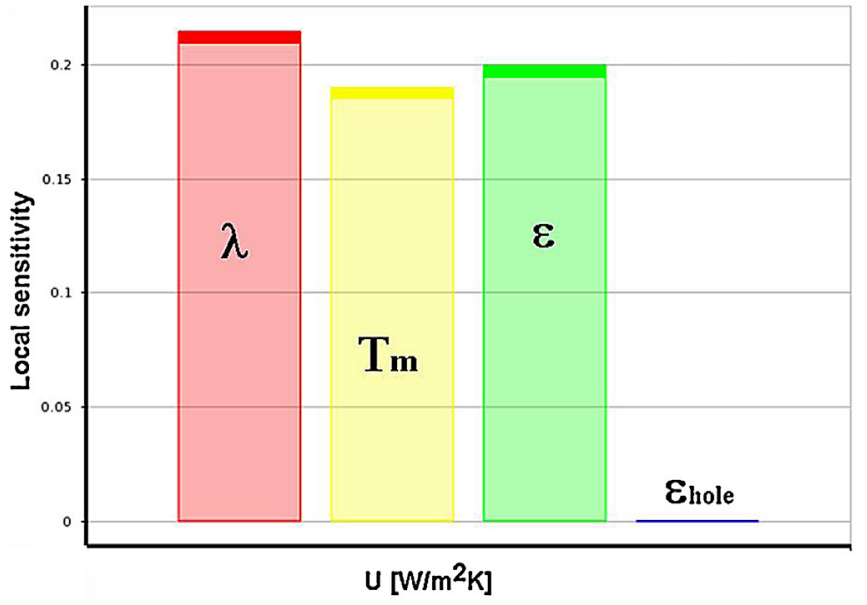

(a)

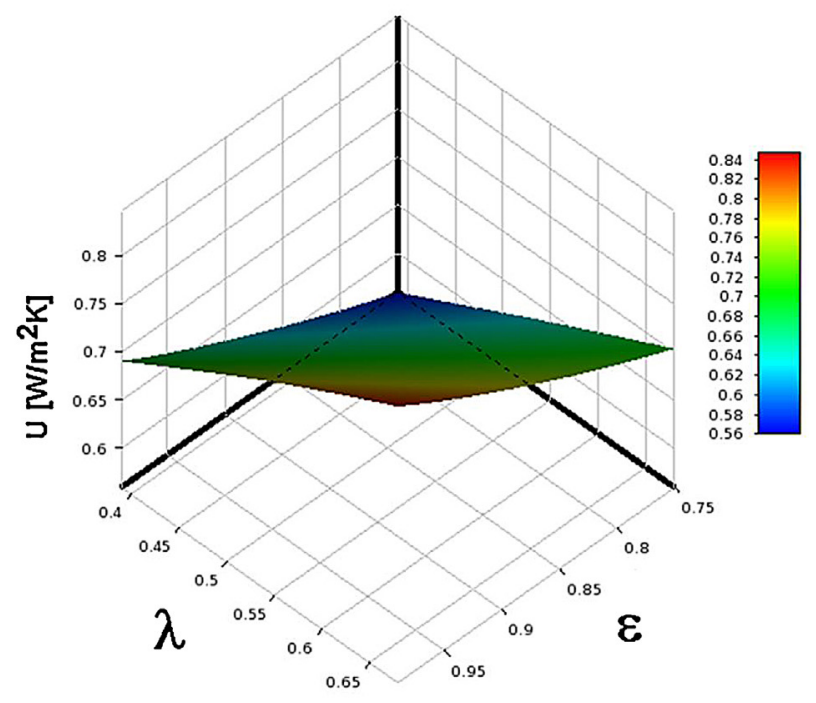

(c)

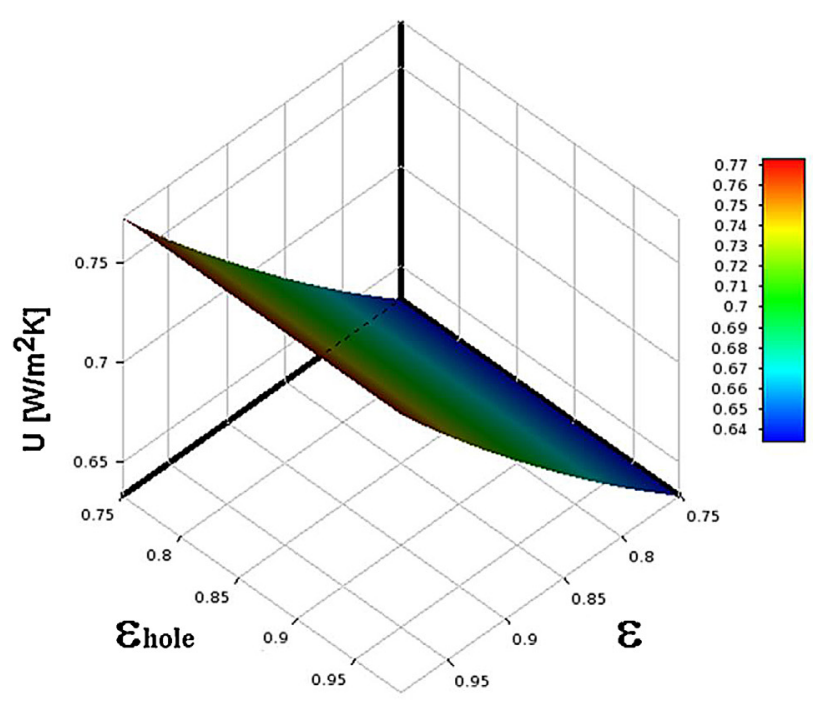

(b)

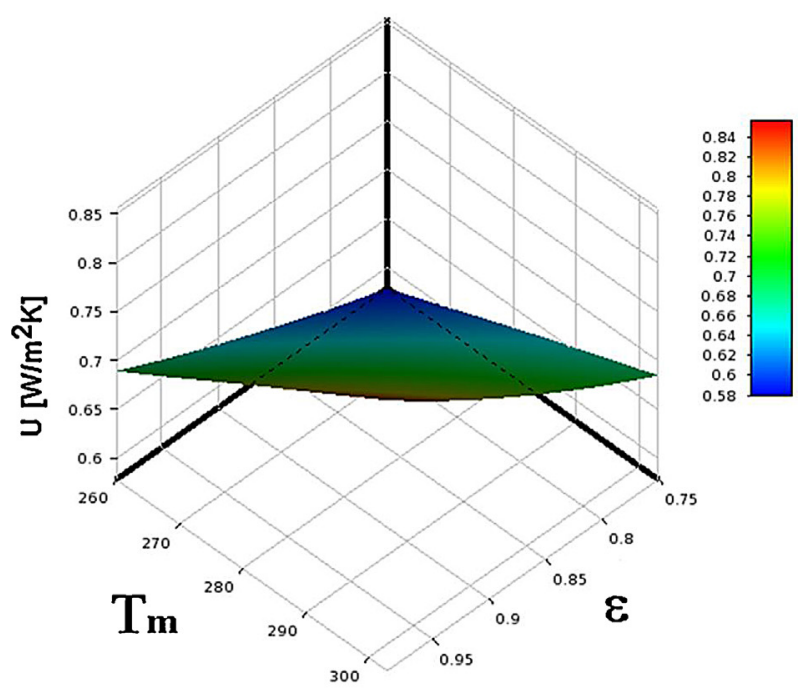

(d)

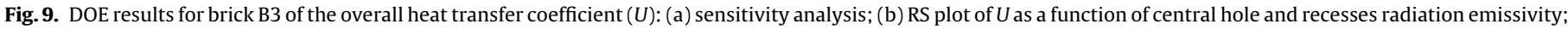

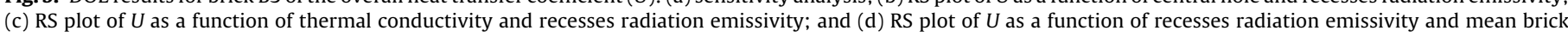
temperature.

\subsubsection{DOE and RSM results}

The application of DOE and RSM leads to development of the predictive RSM. In fact, the RSM procedure can be used for simulation of heat transfer process and the influence of the different variables in the thermal performance of walls made up of bricks B1, B2 and B3. In order to obtain a better understanding of the sensitivity and RSM results, the main findings are presented in Figs. 7-9 as a bar graph and three-dimensional response surface (RS) plots.

Firstly, with respect to the brick B1, Fig. 7a shows the sensitivity diagram for all parameters considered with respect to the overall heat transfer coefficient. Note that the hierarchies of the input variables affecting the thermal transmittance are the following:

- Material thermal conductivity is the most influential variable in a directly proportional way, that is to say, if the thermal conductivity increases the thermal transmittance increase.
- The mean temperature for the black body radiation coefficient is the second influential variable.

- The recesses' surface emissivity coefficient is the third influential variable in a directly proportional way.

- The central (big hole) surface emissivity coefficient is the fourth variable with respect to the thermal transmittance.

Furthermore, Fig. 7b-d shows the response surfaces of the overall heat transfer coefficient, $U$, as a function of all recesses' surface emissivity, as a function of thermal conductivity and recesses' surface emissivity, and as a function of the mean temperature for the black body radiation coefficient and recesses' surface emissivity, respectively. From these response surfaces it is possible to conclude that the thermal transmittance is a monotonically increasing function of the all variables considered. 


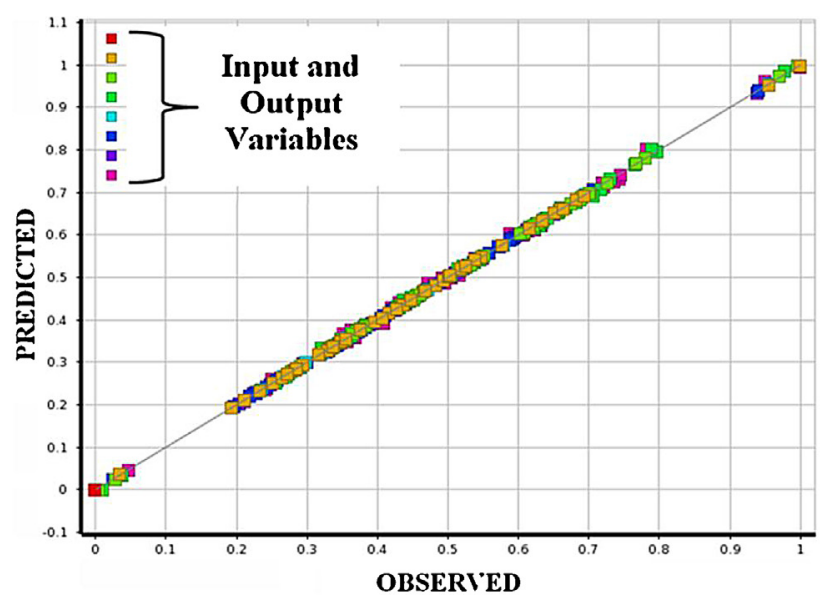

(a) for brick Bl

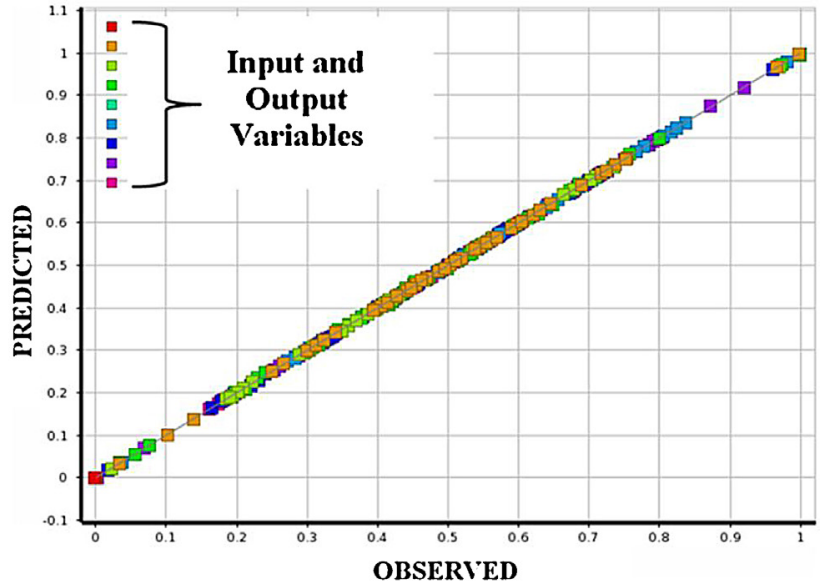

(b) for brick B2

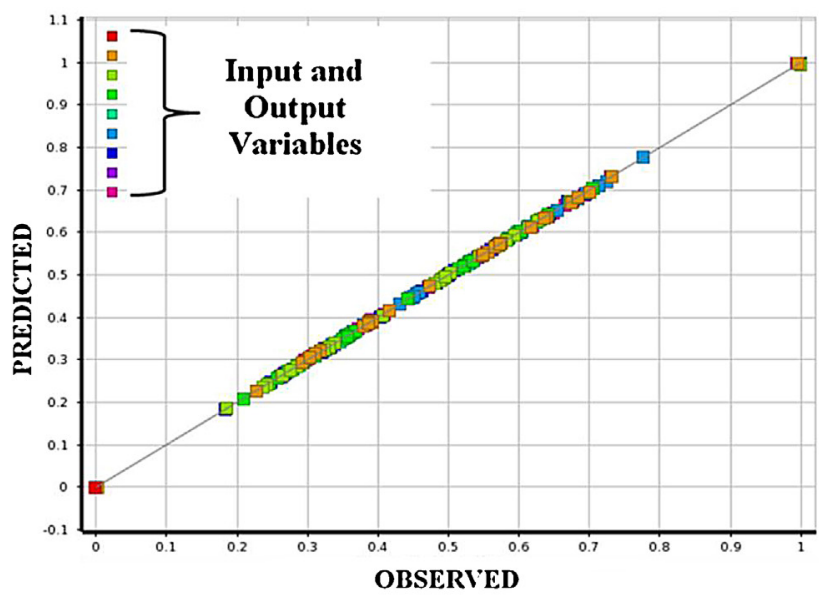

(c) for brick B3

Fig. 10. Goodness of fit: predicted versus observed normalized values.

Thus, to reach a minimum value of the overall heat transfer coefficient it is recommended that the material thermal conductivity and the recesses' surface physical properties are decreased.

Secondly, with respect to the brick B2, the sensitivity diagram for all parameters considered with respect to the overall heat transfer coefficient is presented in Fig. 8a. In this case, the hierarchies of the input variables affecting the thermal transmittance are the following:

- The most influential variable in a directly proportional way is the material thermal conductivity, that is to say, if the thermal conductivity increases the thermal transmittance increase.

- The second influential variable is the mean temperature for the black body radiation coefficient.

- The recesses' surface emissivity coefficient is the third influential variable in a directly proportional way.

- The central (big cavity) surface emissivity coefficient is the fourth variable with respect to the thermal transmittance.

Besides, Fig. 8b-d shows the response surfaces of the overall heat transfer coefficient, $U$, as a function of all recesses' surface emissivity, as a function of thermal conductivity and recesses' surface emissivity, and as a function of the mean temperature for the black body radiation coefficient and recesses' surface emissivity, respectively. From these response surfaces it is possible to conclude that the thermal transmittance is a monotonically increasing function of the all variables considered.

In consequence, to minimize the overall heat transfer coefficient it is necessary that the material thermal conductivity and the recesses' surface physical properties are decreased.

Finally, with respect to the brick B3, Fig. 9a shows the sensitivity chart. It is possible to observe in this diagram the following order of priority for input variables with respect to the thermal transmittance:

- The material thermal conductivity is the most influential variable in a directly proportional way, that is to say, if the thermal conductivity is increased the thermal transmittance increases.

- The recesses' surface emissivity coefficient is the second influential variable in a directly proportional way with respect to the thermal transmittance.

- The mean temperature for the black body radiation coefficient is the third variable in a directly proportional way, with respect to the thermal transmittance.

- Finally, the central (big cavity) surface emissivity coefficient is the fourth influential variable in a directly proportional way, with respect to the thermal transmittance.

Fig. 9b-d shows the response surfaces of the overall heat transfer coefficient, $U$, as a function of all recesses' surface emissivity, as a function of thermal conductivity and recesses' surface emissivity, 
and as a function of the mean temperature for the black body radiation coefficient and recesses' surface emissivity, respectively. From these response surfaces it is possible to conclude that the thermal transmittance is a monotonically increasing function of the all input variables considered.

Accordingly, in this kind of brick the central (big cavity) surface emissivity coefficient plays a negligible influence on the overall heat transfer coefficient. To obtain a minimum value of the thermal transmittance it is recommended to decrease the material thermal conductivity as well as the emissivity coefficient of the recesses'.

\subsubsection{Discussion of the results}

The results obtained showed that the use of paper waste decreased the fired density of the samples down to $1.32 \mathrm{~g} / \mathrm{cm}^{3}$. Their apparent porosity and water absorption values were increased by increasing waste addition. Depending on the increase in the porosity ratios, compressive strengths of the samples decreased. Their strengths were still higher than that required by the standards. Thermal conductivity of the porous bricks produced in this study $(<0.39 \mathrm{~W} / \mathrm{m} \mathrm{K})$ showed more than $40 \%$ reduction compared to local brick of the same composition $(0.68 \mathrm{~W} / \mathrm{m} \mathrm{K})$. Conversion of this product to a perforated brick showed that its thermal conductivity could be decreased down. Results indicated that the paper waste could be easily utilized as pore forming additives into brick bodies to facilitate production of lightweight vertically perforated clay bricks.

In Fig. 10 view, the scatter chart presents, for each output parameter, the values predicted from the response surface versus the values observed from the design points. This figure allows us to determine the response surface goodness of fit with respect to the points calculated in the DOE analysis: the closer the points are to the diagonal line, the better the response surface fits the points. Predicted values of the overall heat transfer coefficient obtained using model equations for the three different bricks were in good agreement with the FEM values. Indeed, a 0.99 coefficient of determination was obtained in this research work (see Fig. 10a-c).

\section{Conclusions}

In this study, industrial recycled paper processing wastes had been used as an additive into an earthenware brick to produce porous and lightweight clay bricks with reduced thermal conductivity and acceptable compressive strength. The mixtures containing clay and the paper waste prepared at different proportions $\left(10,20\right.$ and $30 \%$ by weight) were pressed and fired at $1000^{\circ} \mathrm{C}$. Their density, porosity and water absorption, compressive strength and thermal conductivity measurements were performed.

Design of experiments (DOE), response surface methodology (RSM) and finite element method (FEM) have been implemented in order to build predictive models to study the thermal behavior of various kinds of walls made up of different types of clay bricks mixtures including paper waste.

To minimize the thermal transmittance an enhanced full factorial central composite design (CCD) was used to optimize the values of the input variables: recesses' emissivities, thermal transmittance and mean temperature for the black body radiation coefficient. Results reveal the following main findings:

- The material thermal conductivity of bricks has important influence on the thermal performance, minimizing this physical property gives place to the decrease of the brick thermal transmittance.

- In all analyzed cases, decreasing the surface radiation emissivity of the recesses causes a lower thermal transmittance in the brick.
- For all cases, the central (big cavity) surface emissivity coefficient is the less influential variable.

In summary, the present study has proven that the DOE-RSM techniques in combination with finite element modeling could efficiently be applied to optimize the overall heat transfer coefficient. Furthermore, this methodology is an easy way to obtain the best thermal behavior of different bricks with the fewest number of experiments, in order to obtain important energy saving in building construction. However, as future trend we plan to propose an efficient empirical equation considering the effect of the main influencing parameters on the thermal transmittance.

Finally, engineers and architects can use the main results presented in this research work in order to select the best brick candidate, cavity distribution and clay mixtures for new brick designs.

\section{Acknowledgements}

The authors express deep gratitude to the GICONSIME Research Group at Oviedo University and Turkish Brick Association TUKDER for the brick models and their valuable collaboration. This work was partially financed by the Spanish Ministry of Science and Innovation through the research project BIA2012-31609 co-financed with FEDER funds. Besides we would also like to thank Swanson Analysis Inc. for the use of ANSYS University Research program and Workbench simulation environment.

\section{References}

[1] Energy, transport and environment indicators, Eurostat (2011) (online data code: nrg 100a).

[2] The State Planning Organization (DPT), Ninth Development Plan, Tuğla ve Kiremit Sanayii Alt ÖÍK Raporu (in Turkish), vol. 1, DPT 2773, ÖIK 703, Ankara, Turkey, 2008.

[3] C.A. Balaras, K. Droutsa, A.A. Argiriou, D.N. Asimakopoulos, Potential for energy conservation in apartment buildings, Energy and Buildings 31 (2) (2000) $143-154$

[4] Y. Feng, Thermal design standards for energy efficiency of residential buildings in hot summer/cold winter zones, Energy and Buildings 36 (2004) 1309-1312.

[5] Directive 2010/31/EU of the European Parliament and of the Council on the Energy performance of buildings, Official Journal of the European Union 153 (2010, May)

[6] J.J. del Coz Díaz, P.J. García Nieto, J. Domínguez Hernández, F.P. Álvarez Rabanal, A FEM comparative analysis of the thermal efficiency among floors made up of clay, concrete and lightweight concrete hollow blocks, Applied Thermal Engineering 30 (17-18) (2010) 2822-2826.

[7] M. Zukowski, G. Haese, Experimental and numerical investigation of a hollow brick filled with perlite insulation, Energy and Buildings 42 (2010) 1402-1408.

[8] M. Kornmann, Clay Bricks and RoofTiles: Manufacturing and Properties, Société de l'industrie minérale, Paris, 2007.

[9] M.M. Al-Hazmy, Analysis of coupled natural convection conduction effects on the heat transport through hollow building blocks, Energy and Buildings 38 (2006) 515-521.

[10] E. Rimpel, F. Rehme, Development of extruded, high thermal insulating bricks, Ziegelindustrie International 57 (12) (2001) 36-41.

[11] K. Junge, Additives in the brick and tile industry, Zi Brick and Tile Industry International 53 (12) (2000) 25-39.

[12] E. Rimpel, Industrial production of high-porosity brick materials, Ziegelindustrie International Annual (1996) 174-207.

[13] M. Sutcu, S. Akkurt, The use of recycled paper processing residues in making porous brick with reduced thermal conductivity, Ceramics International 35 (7) (2009) 2625-2631.

[14] EN 832, Thermal Performance of Buildings: Calculation of Energy use for Heating-Residential Buildings, CEN, Brussels, Belgium, 1998.

[15] TS 825, Turkish Standard, Thermal Insulation Requirements for Buildings, Ankara, Turkey, 2008

[16] S.P. Raut, R.V. Ralegaonkar, S.A. Mandavgane, Development of sustainable construction material using industrial and agricultural solid waste: a review of waste-create bricks, Construction and Building Materials 25 (2011) 4037-4042.

[17] M. Dondi, M. Marsigli, B. Fabbri, Recycling of industrial and urban wastes in brick production, Tile and Brick International 13 (3) (1997) 218-225.

[18] M. Sütçü, The use of paper processing residues in the development of ceramics with improved thermal insulation properties (PhD thesis), Izmir Institute of Technology, Turkey, 2010.

[19] A.M. Segadaes, Use of phase diagrams to guide ceramic production from wastes, Advances in Applied Ceramics 105 (1) (2006) 46-54. 
[20] L. Zhang, Production of bricks from waste materials - a review, Construction and Building Materials 47 (2013) 643-655.

[21] O. Gencel, F. Koksal, C. Ozel, W. Brostow, Combined effect of fly ash and waste ferrochromium on properties of concrete, Construction and Building Materials 29 (2012) 633-640.

[22] T. Uygunoglu, I.B. Topcu, O. Gencel, W. Brostow, The effect of fly ash content and types of aggregates on the properties of pre-fabricated concrete interlocking blocks (PCIBs), Construction and Building Materials 30 (2012) 180-187.

[23] O. Gencel, C. Ozel, F. Koksal, E. Erdogmus, G. Martínez-Barrera, W. Brostow, Properties of concrete paving blocks made with waste marble, Journal of Cleaner Production 21 (1) (2012) 62-70.

[24] I. Demir, M.S. Baspınar, M. Orhan, Utilization of kraft pulp production residues in clay brick production, Building and Environment 40 (2005) 1533-1537.

[25] S. Akkurt, M. Sütçü, K. Başoğlu, Isı yalıtım özellikleri iyileștirilmis yap tuğlalarının geliștirilmesinde kağıt üretim atıklarının kullanılması etkileri (in Turkish), in: The 10th HVAC \& Sanitary Congress and Teskon + Sodex Exhibition, The Proceedings of Symposium of Energy Performance in Buildings, Izmir, Turkey, 2011, pp. 899-908.

[26] S.P. Raut, R. Sedmake, S. Dhunde, R.V. Ralegaonkar, S.A. Mandavgane, Reuse of recycle paper mill waste in energy absorbing light weight bricks, Construction and Building Materials 27 (2012) 247-251.

[27] C. Martinez, T. Cotes, F.A. Corpas, Recovering wastes from the paper industry: development of ceramic materials, Fuel Processing Technology 103 (2012) $117-124$.

[28] P. Munoz, M.C. Juarez, M.P. Morales, M.A. Mendiliv, Improving the thermal transmittance of single-brick walls built of clay bricks lightened with paper pulp, Energy and Buildings 59 (2013) 171-180.

[29] L.P. Li, Z.G. Wu, Y.L. He, G. Lauriat, W.O. Tao, Optimization of the configuration of $290 \times 140 \times 90$ hollow clay bricks with 3 -D numerical simulation by finite volume method, Energy and Buildings 40 (2008) 1790-1798.

[30] J.J. del Coz Díaz, P.J. García Nieto, J.L. Suárez Sierra, I. Penuelas Sánchez, Nonlinear thermal optimization and design improvement of a new internal light concrete multi-holed brick walls by FEM, Applied Thermal Engineering 28 (2008) 1090-1100.

[31] J.J. del Coz Díaz, P.J. García Nieto, A. Martín Rodríguez, A. Lozano MartínezLuengas, C. Betegón Biempica, Non-linear thermal analysis of light concrete hollow brick walls by the finite element method and experimental validation, Applied Thermal Engineering 26 (2006) 777-786.

[32] D.C. Montgomery, Design, Analysis of Experiments, 5th ed., John Wiley \& Sons, New York, 2001.

[33] R.H. Myers, D.C. Montgomery, Response Surface Methodology: Process and Product Optimization Using Designed Experiments, 2nd ed., John Wiley \& Sons, New York, 2002

[34] ASTM C20, Standard Test Methods for Apparent Porosity, Water Absorption, Apparent Specific Gravity, and Bulk Density of Burned Refractory Brick and Shapes by Boiling Water, ASTM International, West Conshohocken, PA 2005.

[35] A. Bouchair, Steady state theoretical model of fired clay hollow bricks for enhanced external wall thermal insulation, Building and Environment 43 (2008) 1603-1618.

[36] J.J. del Coz Díaz, P.J. García Nieto, C. Betegón Biempica, M.B. Prendes Gero, Analysis and optimization of the heat-insulating light concrete hollow brick walls design by the finite element method, Applied Thermal Engineering 27 (8-9) (2007) 1445-1456

[37] J.N. Reddy, An Introduction to Non-Linear Finite Element Analysis, Oxford University Press, New York, 2004.

[38] O.C. Zienkiewicz, R.L. Taylor, The Finite Element Method, McGraw-Hill Book Company, United Kingdom, 1991.

[39] K. Bathe, Finite Element Procedures, Prentice-Hall, Englewoods Cliffs, NJ, 1998

[40] UNE-EN ISO 6946, Building Components and Building Elements. Thermal Resistance and Thermal Transmittance. Calculation Method (ISO 6946:2007), 2012.

[41] S. Moaveni, Finite Element Analysis: Theory and Applications with ANSYS Prentice Hall, New York, 2003

[42] E. Madenci, I. Guven, The Finite Element Method and Applications in Engineering using ANSYS, Springer, Berlin, 2005.

[43] UNE-EN 771-1, Specification for Masonry Units - Part 1: Clay Masonry Units 2011.

[44] EN-1934, Thermal Performance of Buildings - Determination of Thermal Resistance by Hot Box Method using Heat Flow Meter - Masonry, CEN, Brussels, 1998.

[45] UNE-EN 1745, Masonry and Masonry Products - Methods for Determining Thermal Properties, 2013. 